\title{
On the Influence of Chinese Newspapers and Periodicals on Japanese Chinese Literature
}

\author{
Jirong Zhang $^{1}$ \\ 1 Department of Chinese Language and Literature, Jinan University, Tianhe District, Guangzhou City, \\ Guangdong Province, China \\ Correspondence: Jirong Zhang. Tel: 86-158-8995-2426. E-mail: aisiyan99r@163.com
}

Received: May 25, 2018

Accepted: June 19, 2018 Online Published: July 27, 2018

doi:10.5539/ass.v14n8p113

URL: https://doi.org/10.5539/ass.v14n8p113

\begin{abstract}
Japanese Chinese literature is a Literature written by overseas Chinese in Japan using Chinese characters. Its emergence and development are related to the Chinese newspapers and periodicals. The Chinese newspapers and periodicals in Japan, represented by the Chinese Review Weekly, provided a platform for the publication of literary works and a spiritual home to the overseas Chinese in Japan. Chinese journals in the Mainland of China, represented by the Fiction World, have played a decisive role in the construction and dissemination of Japanese Chinese literature in Chinese Mainland. Both of them played an important role in the emergence, development, and dissemination of Japanese Chinese literature.
\end{abstract}

Keywords: Chinese Newspapers and Periodicals, Japanese Chinese Literature, Chinese Review Weekly, Fiction World

\section{Introduction}

With the rise of the world immigration tide, ethnic literature and immigration literature (or literature diaspora), have gradually become focal points in the academic community. Since China began to reform and open in the late 1970s, a large number of emigrants have gone overseas. Therefore, Chinese literature has also emerged and developed in many foreign parts of the world. The study of world Chinese literature has also set off an upsurge of research in the Chinese-speaking regions. Research on overseas Chinese literature in the Mainland of China is mainly concentrated in Southeast Asia, North America, and Europe. Research on Northeast Asia is slightly insufficient. However, China and Japan are close neighbors separated only by a strip of water. The two countries have a long history of cultural communications and share the same root in culture. Therefore, it is meaningful and necessary to study Japanese Chinese literature. The present research on Japanese Chinese literature mainly focuses on the analysis of single texts, the analysis of the development context, and the analysis of the motifs. There is nearly no research paper on the relationship between Japanese and Chinese literature and Chinese periodicals. Therefore, this paper attempts to study the influence of Chinese periodicals on Japanese Chinese literature from the perspective of interdisciplinary research, and hopes to provide some information for research in related fields.

As an ideology, literature is inevitably influenced by political and social factors. Hong Zicheng believes that "the production of literature is influenced by certain social factors. For contemporary Chinese literature, the literary institutions (including literary communities and writers' organizations), literary media (including magazines, journals, publishers), identity and existence of writers, and the evaluation mechanism of literature, all of these four factors affect the creation of literature." (Hong, 2015, P.193). Judging from these four perspectives, Japanese Chinese literature is mainly influenced by literary media, and less influenced by literary institutions and evaluation mechanisms. Compared with writers in the mainland of China, the oversea Chinese writers in Japan are freelance writers. They do not belong to a fixed writer organization or institution, they do not enjoy the benefits of literary institutions, at the same time, they can also get rid of the shackles of institutions and are able to create freely. Moreover, the income of most oversea Chinese writers does not depend on writing. They do not write for money but for expression of emotions. Therefore, the writing is also relatively unaffected by the readers and the consumer market. This article mainly discusses the influence of Chinese newspapers and periodicals on Japanese Chinese literature from three aspects: Chinese newspapers and periodicals in Japan, pure literary journals in Japan, and literary journals in Chinese Mainland. It also discusses the important role of Chinese 
newspapers in the production, dissemination and construction of Japanese Chinese literature.

The two concepts in this article need to be described: One is Japanese Chinese Literature: in this article it refers to the Chinese literature written in Chinese by overseas Chinese in Japan. The other is Chinese newspapers and periodicals: in this article it refers to the Chinese newspapers and periodicals that are published both in japan and Chinese Mainland.

\section{Method}

The research in this paper mainly uses three methods: content analysis, personal interview and case study. The content analysis method can also be called quantitative analysis method. It mainly uses reliable data facts to make the general fuzzy media text clear and precise, thus providing a basis for interpretive analysis. This article analyzes the quantitative analysis of Japanese and Chinese literary works published in Chinese newspapers and periodicals to reflect the role played by Chinese newspapers and periodicals in the creation and development of Japanese and Chinese literature. Individual interviews are interviews with eyewitnesses to parties or events. Some of the data and the description of literary events in this article were obtained by interviewing some of the responsible persons and some authors of the Chinese newspapers and periodicals. The case analysis method focuses on the analysis of certain phenomena and events from the micro level to obtain more detailed analysis and understanding of the problems. The main cases in this article are the three Chinese-language periodicals Chinese Review Weekly, Fiction World, and Blue.

\section{Discussion}

\subsection{The Influence of Chinese Newspapers and Periodicals in Japan on Japanese Chinese Literature}

In the early 20th century, the Chinese Newspapers and Periodicals in Japan play a very important role in the development of modern Chinese literature. It breeds many modern Chinese writers and contributed to the modern transformation of Chinese literature. After the 1980s, the Chinese Newspapers and Periodicals in Japan not only provided information to Chinese in Japan, but also provided a platform for Japanese Chinese to write on homesickness and promoted the spread of Chinese literature and culture in Japan.

After the defeat of the Sino-Japanese naval battle in 1894, China began dispatching students to Japan to study Western science and technology in 1896 in order to enrich the nation and save the country. At the time of the new and old revolutions, the spread of new ideology and new cultures became very urgent. Students studying in Japan and the exiles (mainly politicians and revolutionaries) fully realized the importance of newspapers and magazines for ideological and cultural communication. So Chinese newspapers and magazines in Japan emerged. According to statistics, "Since Liang Qichao founded the Qing Commentary in 1898, as of the revolution of 1911, there were more than 60 magazines published by Chinese people in Japan. Only in 1907, there were 21 kinds of Chinese newspapers and periodicals founded in Japan" (Sanetou, 2012, PP. 291-294).

These Chinese newspapers and periodicals have not only become mouthpiece for revolution and politics, but also become major promoters of the modern transformation of Chinese literature. There are quite a number of literary publications in these publications. For example, the New Novel founded by Liang Qichao in 1902 was the earliest periodical of special feature novels and played an active role in promoting the creation and translation of novels. Lu Xun, the father of Chinese Modern Literature, wrote articles for Chinese magazines such as Zhejiang Tide and Henan during his time in Japan. The Creation Society, which was of great significance in the history of modern Chinese literature, was established in Tokyo in 1921. Only this literary society founded four publications including Create Quarterly, Create Monthly, Create Weekly, and Create Day. After 1931, as the number of students studying in Japan decreased, the number of Chinese journals in Japan decreased. Most of them were revolutionary publications, and literary publications were relatively few.

After the normalization of diplomatic ties between China and Japan in 1972, Sino-Japanese relations have improved. Chinese newspapers and periodicals in Japan have also developed. After the reform and opening up, more and more Chinese people went to Japan, and there were more and more Chinese newspapers and periodicals. According to Cheng: Only from 1985 to 1996, there were 77 kinds of Chinese newspapers and periodicals in Japan, of which more than 20 were still issued until the middle and late 1990s (Cheng, 2001, PP.306-307). As life became more stable, the Chinese writers in Japan began to write their experiences in Japan and nostalgia for China, and the works began to be published frequently in Chinese newspapers and periodicals. Most Chinese newspapers and periodicals in Japan not only provide a variety of news and life information, but also provide a literary and cultural column for the Chinese in Japan. It provides a platform for Chinese to express homesickness and their exotic living experience, and it also builds a spiritual home for the Chinese in Japan.

According to Zhang Shi, a Japanese Chinese who have been working in the media, the deputy chief editor of the 
Chinese Review Weekly, introduced Chinese newspapers and periodicals in Japan such as Foreign Student News, Chinese Students, China-Japan News, Chinese Review Weekly, and The Japanese Chinese News, The Oriental Times, The Chinese Times, The New World, The New Chinese Daily all published the essays, poems, novels and other literary works created by Chinese in Japan. Take the most-widely read Chinese newspaper Chinese Review Weekly published in Japan as an example. Its literary section is mainly composed of "Literature", "PEN" (full name is the Japanese Chinese Literary PEN) and "Japanese Years". There are two sources of articles in the literary section. One is the submission of articles by readers, and the other is the excellent works of PEN members. At the same time, newspapers also recommend excellent writers to join the PEN (Yang, 2001, P.52). For example, in the Sakura season of 2017 and 2018, the cherry tree album of the PEN members was released for two consecutive years. In the Spring Festival of 2017, the Spring Festival album of the PEN members was launched. The literary section of the supplement of the Chinese Review Weekly not only provides an emotional paradise for the Chinese in Japan, but also provides a platform for the publication of Japanese Chinese writers. For example, the new immigrant writers Chen Yonghe, Li Changsheng, Zhang Shi, Hua Chun, and Wofoo Yayoi, Lin Qi, Chun Ye, Li Yutan, Hei Hai, Mao Danqing, Wan Jinglu, Tang Xinzi, and Du Hailing have all been publishing works in the Chinese newspapers and periodicals such as the Chinese Review Weekly. Zhang Shi's novels, such as The Sadness in Tokyo, Three Sisters and Love of Indra, were all serialized by Chinese Review Weekly and then published by Chinese Review Weekly Press.

After the emergence of Internet media, Chinese newspapers and periodicals in Japan produced electronic publications correspondingly, established websites, and used the new online media to increase the propagation. In addition, pure network media has gradually increased. For example, the Japanese Mirror, established in April 2006, is a free and active new media. It uses a blog site (www.dongyangjing.com) as a platform. The main content of the website is the personal collection of the Chinese writers in Japan, and also the articles and comments on Japanese topics written by the experts and scholars, Chinese students in Japan, foreign labor workers and so on. The participants are mainly journalist editors and columnists active in Japanese Chinese media. The purpose of the website is "Take the Japan as a mirror and mirror the Japan", hoping to reflect the life and thinking of the Chinese in Japan in the most free, flexible and efficient way (Zhou, 2007, P. 13).

\subsection{Chinese Pure Literary Journals in Japan Adheres to Literariness}

In addition to commercial media and newspapers in Japan, there have also appeared pure literary publications founded by overseas Chinese living in Japan. These publications carry the literary dream and their steadfastness to literariness. They also play an important role in the development and prosperity of Chinese literature in Japan. Since the reform and opening up, two pure literary publications that have appeared in Japan were Desert Island and Blue.

Desert Island was the first pure literary periodical in Japan in 1990. It was initiated by Chinese students in Japan, such as Sun Lichuan, Wang Zhongchen and Lin Qi. It was mainly published well-written literary works of the Japanese Chinese people, especially poetry, and was dedicated to promoting the development of Japanese Chinese literature. A total of 4 issues were issued. The publication named Desert Island derives from two considerations. One is that the students studying in Japan "are far away from their homeland and are nostalgic and exotic" and the second one is that modern people "have felt profound loneliness in the rhythm and complexity of modernization. They hope that the publication can become an oasis in desolate and bring comfort to people." (Lin, 2014, P.140) The publication pursues a pure literary ideal and hopes to use poetry and purified language to resist the roughness of the media language in the new era. They hoped to practice the oasis of poetry with the creation of pure literature.

Blue is a comprehensive quarterly journal on culture and literature issued in both Chinese and Japanese. Four overseas Chinese students who studied in Japan initiated the publication. They were Li Zhangang, Liu Xiaofeng, Liu Yanzi, and Qin Lan. The first issue was published in August 2000. The founding words introduced the ideal and purpose of the journal that is to jointly build a "blue literature" worthy of the world and China through the interactive cooperation of editors, authors and readers. They insisted on the position of purely literary periodicals and refused to intervene in commercial politics. All publishing costs relied on the journalists' meager scholarships and part-time income, and the unpaid sponsorship of friends. The journal Continued to the rest of the year until 2006 and published a total of 21 issues. It adheres to a pure and independent literary and cultural stance. In the form of an album or column, it introduces the important writers and works of the three countries of China, Japan, and South Korea, as well as other countries' pure literary works. It also publishes literary criticism in appropriate amounts, and tries to experiment with the "reading of different places" of the same work. This kind of experiment is pioneering. In addition, the publication is the only comprehensive literary and cultural publication in the history of Sino-Japanese exchanges in the last one hundred years that used two languages to 
introduce the comparative literature in China, Japan and South Korea (Li, 2016).

\subsection{The Dissemination and Promotion of Japanese Chinese Literature by the Literary Publications in the Mainland of China}

In the 1980s and 1990s, overseas Chinese literature was very popular in the Mainland of China. Chinese literary periodicals, as an important communication medium, actively participated in the imagination and construction of "overseas Chinese literature" and played an important role in promoting the production and dissemination of overseas Chinese literature. As a part of overseas Chinese literature, Japanese Chinese literature is inevitably affected by the periodicals in the Mainland of China.

After the reform and opening up, foreign intellectuals and information flowed into the Mainland of China. People experiencing a long-term repression are full of yearning for the foreign world. Many Chinese people embarked on the road of studying abroad with the desire for knowledge and the mentality of going abroad. In the days of studying abroad, in the face of different cultural conflicts, the hardships of overseas life, the susceptibility to rooting and replanting, and the homesickness far from home, there is a strong desire to write. For overseas students, the days of study abroad has created a strong desire for writing in the face of different cultural conflicts, the hardships of overseas life, the susceptibility to rooting and replanting, and homesickness far from home. Meanwhile, people who can't go abroad are full of curiosity about overseas life. Therefore, the literature of overseas students rose around the 1990s and became popular. It has entered the vision of Chinese people and has become an important part of Chinese contemporary literature.

A Native Of Beijing In New York is a novel written by a Chinese in the United States. It is a story of a group of native of Beijing who immigrated to the United States and worked hard in the United States. The hero is an outstanding violinist in China, in the United States. He can only work in Chinese restaurants. After many years of hard work, he finally has a rich material life, but no longer feel happy and peaceful. The novel was first serialized in the Beijing TV News, and published by Chinese Literature Publishing Company in 1991. In 1993, it was awarded the "Flowers Film Awards" established by the Fiction Monthly. In the same year, it was made into a TV series. Through watching television, people learned about the life of overseas Chinese. A Native Of Beijing In New York has great repercussions in the Mainland of China and becomes a household name, which has led to the imitation of other overseas writers. Such works include Fan Xiangda's A Native of Shanghai in Tokyo, Li Huixin's Bright is the Moon over My Home Village: A Native Of Beijing Girl in Tokyo and Mei Lan's Meilan in Tokyo in Japanese Chinese literature.

In the 1980s and 1990s in China, Chinese literary journals face fierce market competition. Editors of publications know the readers' curiosity about overseas life. So they actively promoted overseas students' works depicting overseas life. In this period, publications published in overseas Chinese literature were mainly in Beijing, Shanghai, and Guangzhou etc. These literary such as Harvest, Shanghai Literature, Fiction Word, Encounter Monthly, October, People's Literature, Beijing Literature, Flower City, Literature and Art of Guangzhou, Special Zone Literature, etc. have published a large number of overseas students' literary works. After 2000, with the increasing level of overseas Chinese writers' creative works, domestic and foreign scholars increasingly studying on overseas Chinese literature, and the influence of overseas Chinese literature in China is also increasing. The works of overseas Chinese writers are also increasingly published or issued in domestic literary publications.

The Fiction World played an important role in the publication and dissemination of overseas Chinese literature. In 1984, it began to publish literary works written by overseas students sporadically. In 1987, it opened the "Extractive Works of Overseas Chinese Writers" column. In the first period of 1988, it published the summary of the symposium about the literature of Chinese overseas students organized by the Morningside Club, a Chinese student community in the United States (Tang, 2015, pp. 197-198), and the column of "the literature of Chinese overseas students" was first set up (Until 2004). According to Wang, the column specializes in publishing literary works by overseas students and systematically promotes the works of writer's such as Xiao Zha, Wang Yu, Jian Ni, Dai Fang, Wu Minmin, Li Pei, Yu Meng, Yan Li, Xiao Cao, Shi Guoying, and Wang Lufu, etc. The Fiction World also organizes seminars on overseas students' literature and publishes a number of domestic and foreign scholars' professional review articles on overseas students' literature. It contributes greatly to the construction and promotion of overseas Chinese literature in the mainland of China. (Chen, 2000, p. 8)

The rising and booming of Japanese-Chinese literature has a lot to do with the promotion of domestic publications and publishers. There are four Japanese Chinese writers in the writers promoted by the Fiction World. In the book of Chinese Overseas Students' Literature Collection of Contemporary Novel in Japan and Oceania, there are 14 works written by Japanese Chinese writers, including 13 short stories and one excerpt of 
the novel. The publication time of these works is concentrated between 1989 and 1996, mainly in Chinese newspapers and magazines in the mainland of China and Japan. In the 14 selected works, there are 6 works published in the Journal of the Fiction World, one in Harvest and one in Shanghai Literature, 2 novels published by domestic publishing houses, 2 works in the Chinese newspaper in Japan named Foreign Students News, and 2 in the pure literary journal named Desert Island in Japan. These Chinese literary works are much more sensitive to the learning life in Japan. The main tendency is to show the readers the difficulty and hardships of the life in Japan.

After 2000, with the stability of the writer's life, the subject of literary creation changed from foreign students to people who settled in Japan after graduation. Their vision was broader, and their experience of Japan was more leisurely and calm. They have more time to polish their works, so the works have more literariness and artistry, and there have been more publications in domestic journals. In Japanese Chinese literature, essay creation is rich, essay writers are high profile and their achievements are relatively bigger. Most of the essay writers in Japan began with an essay column on essays introducing Japanese culture and customs. After having gained popularity, they then assembled and published the articles. In Japan, writers who mainly write essays are Li Changsheng, Mao Danqing, Jiang Jianqiang, Wan Jinglu, Zhang Shi, and Tang Xinzi. They are all columnists of Chinese media in the mainland of China and Japan. Most of these column essays are from the perspective of comparison between China and Japan, some focusing on reading notes (such as Li Changsheng), some on historical materials (such as Jiang Jianqiang), and some on learning from the fragmentation of life (such as Wan Jinglu), etc. They comprehensively introduce Japanese culture and customs. In addition to these essay writers, the writers who mainly write novels such as Chen Yonghe, Hua Chun, and Yi Fu also wrote prose and published in many domestic newspapers and journals.

Since the 21 st century, besides the great achievements in essay writing, Chinese writers in Japan have also performed well in the creation of novels, and have published many articles in major domestic literary publications. For example, Ha Nan has published novels and stories in important domestic literary publications such as October, Chinese Writers, Harvest, Shanghai Literature, Mountain Flowers, Zhongshan Literary Bimonthly, and Beijing Literature since 2000, and a novella collection of Hokkaido published by Beijing Writer press in 2015. Since 2015, a woman writer Chen Yonghe has published two novels and one short story in Harvest magazine and one short story in Fujian Literature.

\section{Conclusion}

As an ideological and spiritual product, literature is always influenced by various social factors, such as the living environment of the writers and the publishing platform. Especially in the era of modern consumer society, literature is linked to publishing, marketing, readers, etc. The Chinese writer in Japan is mainly composed of overseas students studying in Japan and those who stayed in Japan after graduation. They are eager to integrate into Japanese society, at the same time, it is difficult to forget the memories and growth experiences in China that are soaked in their blood, which become the source of their literary creation. The experience in Japan makes their literary works exhibit a diaspora experience and a perspective of others, which makes Japanese Chinese literature different from the literature characteristics of the mainland of China. Chinese literature has become the spiritual sustenance of Japanese immigrants to express their feelings in their hearts and minds. Japan's Chinese periodicals and Chinese literary periodicals provide a platform for the writing of Japanese Chinese writers and also participate in the imagination and construction of Japanese Chinese literature. They played an important role in promoting the rise, development and prosperity of Japanese Chinese literature.

\section{References}

Chen, J. T. (2000). Preface Two. In Z. P. Wang (Ed.), Chinese Overseas Students' Literature Collection of Contemporary Novel in Japan and Oceania (pp. 7-17). Shanghai: Shanghai Literature and Art Publishing House.

Chen, M. L. (2011). Research on Overseas Chinese Media. Beijing: Xinhua Publishing House.

Hong, Z. C. (2015). Problems and Methods. Beijing: SDX Joint Publishing Company.

Li, Z. G. (2016). I and BLUE, a paper presented in the conference on New Century, New Development, New Trends: Seminar on Japanese Chinese Literature, held at Jinan University in June 14, 2016.

Lin, Q. (2014). From "rise" to "drifting": A study on new overseas Chinese poems in Japan. The Literary Disputes, (6), PP138-147.

Sanetou, K. S. (2012). The History of Chinese Studying in Japan (Tan, R. Q \& Lin, Q. Y. Trans.). Beijing: Peking University Press. 
Tang, Y. M. (2015): Little Stories in a Big Age. Nanjing: Nanjing University Press.

Yang, W. K. (2001). The History of Chinese Review Weekly: A microcosm of the development of Chinese media in Japan. In China News Service (Ed.), The First Forum on the Global Chinese Language Media Proceedings (pp. 45-53). Hong Kong: Hong Kong China Press Publishing.

Zhou, Z. C. (2007). New space New network New role: Effects of blogs on the interaction between Chinese migrants and China. Overseas Chinese History Studies, (4), 11-17.

\section{Copyrights}

Copyright for this article is retained by the author(s), with first publication rights granted to the journal.

This is an open-access article distributed under the terms and conditions of the Creative Commons Attribution license (http://creativecommons.org/licenses/by/4.0/). 